Revista de Ciencias Sociales - Número 62 (2013) - Páginas 13-37

Constitución, orden público y tendencias legislativas recientes

\title{
CONSTITUCIÓN, ORDEN PÚBLICO Y TENDENCIAS LEGISLATIVAS RECIENTES
}

\author{
CONSTITUTION, PUBLIC ORDER \\ AND RECENT LEGISLATIVE TRENDS
}

\author{
NICOLL ROJAS LABRA* \\ nicollrojasl@gmail.com \\ DIANA VALDÉS AGUAYO* \\ diana.valdes.a@gmail.com \\ Universidad de Valparaíso
}

\section{Resumen}

Este artículo pretende demostrar que los proyectos de ley en materia de orden público que se encuentran en la Comisión de Seguridad Ciudadana y Drogas reflejan una tendencia legislativa expansionista del derecho penal en la política criminal chilena, la que vulnera derechos fundamentales consagrados en la Constitución Política. Estos derechos son el principio de legalidad, la responsabilidad individual de las penas, el derecho a no autoincriminarse, la garantía de protección judicial, el derecho a la libertad personal y seguridad individual, la libertad de conciencia, el derecho a la no discriminación arbitraria y la libertad de expresión y de opinión.

\section{Palabras claves}

Inconstitucionalidad, tendencia legislativa penal, expansión del derecho penal, vulneración de derechos fundamentales.

\footnotetext{
* Egresadas de la Escuela de Derecho de la Universidad de Valparaíso. Artículo recibido el 23 de mayo de 2013 y aceptado el 25 de junio de 2013.

Revista de Ciencias Sociales - Número 62 (2013) - Universidad de Valparáíso - ISSN 0716-7725-Valparáiso, Chile
} 


\begin{abstract}
This article aims to demonstrate that public order bills in the Citizenship and Drugs Safety Commission reflect an expansive legislative trend of criminal law and Chilean criminal politic, which violates the human rights enshrined in the Constitution. These rights are the rule of law, the individual responsibility of penalties, the right of personal freedom and individual safety, freedom of conscience, the right to non-arbitrary discrimination and freedom speech.
\end{abstract}

\title{
Keywords
}

Unconstitutional bills, criminal legislative trends, criminal law expansion, violation of human rights.

\section{Introducción}

La política criminal del Estado de Chile, durante las últimas dos décadas, ha seguido una determinada tendencia legislativa penal en cuanto al fortalecimiento del resguardo del orden público, la que principalmente se configura en la creación de nuevos tipos penales, el aumento de las penas ya existentes y la flexibilización en los procedimientos que compete realizar a las policías. Considerando que las sanciones del derecho penal pueden restringir o privar ciertos derechos fundamentales consagrados en nuestra Carta Magna, y cuyo fundamento es el carácter antijurídico de los hechos cometidos por el sancionado, es menester determinar los límites que tiene el derecho penal como última ratio en relación a la protección de los derechos fundamentales.

Mediante el análisis de siete proyectos de ley tramitados entre el año 2010 a 2012 se busca identificar los derechos fundamentales que se vulneran a consecuencia de esta tendencia legislativa. Ellos son derechos relacionados con las garantías constitucionales de índole penal manifestadas en el respeto al principio de legalidad, la responsabilidad individual de las penas, el derecho a no autoincriminarse, la garantía de protección judicial, libertad personal y seguridad individual, libertad de conciencia, derecho a la no discriminación arbitraria y libertad de expresión y de opinión. Concluiremos que el articulado de esta

Facultad de Derecho y Ciencias Sociales - Universidad de Valparaíso - Chile 
tendencia legislativa es inconstitucional ya que en un examen previo de constitucionalidad los proyectos de ley contemplan la restricción ilegítima de derechos fundamentales consagrados en la Constitución y en tratados internacionales.

Los proyectos de ley analizados son los siguientes: Boletín 701825, que sanciona con mayor rigor las falsas alarmas públicas; Boletín 7155-25, que sanciona a quienes participen en desórdenes públicos con el rostro cubierto; Boletín 7290-25, que agrava la responsabilidad penal del que daña cámaras de televigilancia; Boletín 7895-25, que modifica el procedimiento del control de identidad; Boletín 7975-25, que fortalece el resguardo del orden público; Boletín 8223-25, que penaliza la interrupción del tránsito con fines coactivos, y Boletín 8420-25, que modifica el delito de desórdenes públicos.

\section{La in-constitucionalidad de la tendencia legislativa: el principio de legalidad}

Del análisis de los siete proyectos de ley presentados a la Comisión permanente de Seguridad Ciudadana y Drogas, podemos observar que la tendencia legislativa contenida en ellos vulnera principios relacionados directamente con el derecho a un debido proceso garantizado en la Constitución ${ }^{1}$. Así, en primer lugar, los proyectos en revisión comprometen el principio de legalidad de los delitos y las penas, que se encuentra consagrado en el artículo 19 número 3 inciso $8^{\circ}$ y $9^{\circ}$ de la Constitución Política de la República² (en adelante "CPR”), en el artículo 9 de la Convención Americana de Derechos Humanos ${ }^{3}$ (en

1. Se analizan los boletines $\mathrm{N}^{\circ}$ 7018-25, 7155-25, 7290-25, 7895-25, 7975-25, $8223-25$ y $8420-25$.

2. "Ningún delito se castigará con otra pena que la que señale una ley promulgada afectado. con anterioridad a su perpetración, a menos que una nueva ley favorezca al

Ninguna ley podrá establecer penas sin que la conducta que se sanciona esté expresamente descrita en ella”.

3. "Nadie puede ser condenado por acciones u omisiones que en el momento de cometerse no fueran delictivos según el derecho aplicable. Tampoco se puede

Revista de Ciencias Sociales - Número 62 (2013) - Universidad de Valparáíso - ISSN 0716-7725-Valparaíso, Chile 
adelante "CADH"), en el artículo 15.1 del Pacto Internacional de Derechos Civiles y Políticos ${ }^{4}$ (en adelante "PIDCP"), en el artículo 1 inciso tercero y artículo 18 inciso $1^{\circ}$ del Código Penal ${ }^{5}$ (en adelante "CP"). Este principio "garantiza al individuo y constituye un límite al Estado en el ejercicio del ius puniendi, en aras a que éste sólo puede castigar un hecho cuando una ley anterior a la ejecución del mismo lo describe como delito y precisa cuál es la pena que debe aplicarse a quien lo realiza" ${ }^{\circ}$.

La ley para constituirse como fuente de delitos y penas debe cumplir con tres exigencias: debe ser previa, escrita y estricta. Que sea previa, implica una prohibición de retroactividad; que sea escrita conlleva que sólo puede ser fuente legal del derecho penal la ley propiamente tal; y que sea estricta hace alusión a la prohibición expresa de la analogía ${ }^{7}$. Por ello, a continuación, revisaremos dos expresiones del principio de legalidad que se ven vulnerados en la tendencia legislativa en comento. Estas son el principio de tipicidad y el principio de ofensividad.

El principio de tipicidad, determinación o taxatividad es una garantía constitucional que requiere que la ley penal al crear delitos y

imponer pena más grave que la aplicable en el momento de la comisión del delito. Si con posterioridad a la comisión del delito la ley dispone la imposición de una pena más leve, el delincuente se beneficia con ello".

4. Este artículo está redactado en términos casi idénticos al de la CADH, antes citado.

5. "El que cometiere delito será responsable de él e incurrirá en la pena que la ley señale, aunque el mal recaiga sobre persona distinta de aquella a quien se proponía ofender.

Ningún delito se castigará con otra pena que la que le señale una ley promulgada con anterioridad a su perpetración”.

6. GARRIDO, Mario: Derecho Penal, parte general, Tomo I, Primera Edición. Editorial Jurídica de Chile, Santiago de Chile, 2001. Pág. 31.

7. NÁQUIRA, Jaime et al: "Principios y penas en el derecho penal chileno". En: Revista electrónica de ciencia penal y criminología, Universidad Católica de Chile, Santiago de Chile, 2008. Pág. 5. Disponible en: http://criminet.ugr.es/recpc/ 10/recpc10-r2.pdf. Fecha última consulta: 03 de marzo de 2013.

Facultad de Derecho y Ciencias Sociales - Universidad de Valparaíso - Chile 
penas se refiera directamente a los hechos que constituyen un ilícito penal, lo que se conoce como principio de taxatividad o tipicidad, consagrado en el artículo 19 número 3 inciso $8^{\circ}$ de la CPR, que exige que la conducta sancionada por ley esté expresamente descrita. Por lo tanto, están prohibidos los tipos penales abiertos y las leyes penales en blanco, ambos serían inconstitucionales, el primero, al no describir con exactitud la conducta que se considera delito y el segundo, al remitir la descripción de la conducta o la imposición de la pena a una fuente formal inferior, como un reglamento administrativo o un decreto ley.

De los proyectos de ley analizados pudimos observar una tendencia por parte del legislador a vulnerar la garantía constitucional de reserva legal y de tipicidad. La reserva legal se infringe en el boletín 7895-25 al tipificar en el Código Procesal Penal (en adelante "CPP”), mediante la modificación del artículo 85 sobre procedimiento de control de identidad, un hecho considerado antijurídico, que no es delito ni falta, que sin embargo es un presupuesto para que los funcionarios policiales procedan a efectuar la detención sin orden previa del individuo. En este boletín se autoriza la detención de una persona, en caso de que éste se encuentre encapuchado u oculte su rostro, y en el fondo, pretende equiparar esta situación a la negación de la identidad, falta tipificada en el artículo 496 número 5 que en virtud del artículo 134 del $\mathrm{CPP}^{8}$ es una de las faltas que autorizan la procedencia de la detención como medida cautelar. Ello se reafirma al señalar que la persona que niega su identidad o se encontraba encapuchada será detenida, conducida a la unidad policial cercana y tendrá los mismos derechos que un detenido. Sin embargo, esta conducta "andar encapuchado" al no ser una falta ni constituir ningún ilícito penal —no puede autorizar la detención_-, de manera que por este hecho el Ministerio Público no puede formalizar, porque es un acto atípico, y como en el derecho penal la analogía está proscrita, no se puede asociar la negación de identidad con la ocultación del rostro mediante vestimentas, porque la ocultación del rostro es atípico y si la ley no lo

8. Este artículo enumera taxativamente las faltas que autorizan la detención como medida cautelar, haciendo excepción al artículo 124 del CPP que señala que la medida cautelar por excelencia de las faltas es la citación.

Revista de Ciencias Sociales - Número 62 (2013) - Universidad de Valparáíso - ISSN 0716-7725-Valparáiso, Chile 
contempla como delito no cabe al funcionario policial considerarlo como tal.

El principio de tipicidad, luego, exige que la conducta considerada como delito debe señalarse expresamente; así, según Garrido las descripciones vagas o demasiado generales no cumplen con el mandato de determinación ${ }^{9}$, siendo infringido mediante la creación de tipos penales abiertos, que describen el núcleo típico de manera tan amplia que cualquier conducta puede adecuarse al tipo penal. En materia de infracciones al orden público, la tendencia legislativa pretende eliminar dos requisitos del tipo penal actual, el primero de ellos es la gravedad de la turbación a la tranquilidad pública y el segundo es el ánimo de ofender el orden público, es decir, el dolo debe captar la ofensa de ese bien jurídico en específico, ya sea mediante la lesión o la puesta en peligro del orden público, y este requisito se manifiesta con la turbación grave para causar injuria a otra persona o con cualquier otro fin reprobado por el ordenamiento jurídico.

Sin embargo, la tendencia legislativa tiende a crear una especie de responsabilidad objetiva en materia de desórdenes públicos. Así el boletín 7975-25, señala abiertamente que serán sancionados con pena de presidio en su grado medio los que "participen en desórdenes o en cualquier otro acto de fuerza o violencia cuando concurra alguna de las circunstancias enumeradas"10; y el boletín 8223-25, sanciona la irrupción ilegítima del tránsito "cuando ella tenga por fin solicitar en forma coactiva una prestación de cualquier naturaleza" ${ }^{11}$. Luego, el principio de tipicidad exige que se exprese taxativamente cuál es la conducta que configura el tipo penal, de manera que, de la sola lectura del artículo una persona pueda identificar qué conducta se considera antijurídica y la pena asociada para tal acto. De la lectura de ambos artículos citados, es improbable que se pueda identificar con precisión

\section{GARRIDO, Mario: ob. cit. Pág. 32.}

10. Boletín 7975-25, que fortalece el resguardo del orden público, 2011. Pág. 15.

11. Boletín 8223-25, que penaliza la interrupción del tránsito con fines coactivos, 2012. Pág. 2.

Facultad de Derecho y Ciencias Sociales - Universidad de Valparaíso - Chile 
la conducta que se adecúa al tipo de desórdenes públicos, porque ésta no se encuentra determinada.

En el boletín 7975-25, en primer lugar, ni siquiera puede identificarse el sujeto activo del tipo, es decir, no hay autor sino que hay partícipes, se castiga a quien participa, de manera que, en términos amplios, partícipes puede ser el cómplice, encubridor, instigador, entre otros. En segundo lugar, se castiga a los que participan en desórdenes o en actos de fuerza o violencia, no exige que los desórdenes sean de cierta entidad, y los actos de fuerza o violencia ni siquiera exigen la ofensa al orden público. Es evidente que el delito no exige ningún requisito en cuanto a la gravedad de los desórdenes o de los actos de fuerza o violencia. En relación a este proyecto de ley, el 12 de julio de 2012 la Comisión de Seguridad Ciudadana y Drogas de la Cámara de Diputados solicitó la opinión de la Corte Suprema en virtud del artículo 77 inciso $2^{\circ}$ de la CPR y el artículo 16 de la ley número 18.918, Orgánica Constitucional del Congreso Nacional, que establecen la obligación de oír previamente a la Corte antes de la votación del proyecto de ley respectivo cuando se refiere a materias de organización y atribución de los tribunales. En el análisis del proyecto que se hace en el oficio en comento, los Ministros señores Dolmestch, Brito y Cerda lo informan desfavorablemente, fundamentando en que la modificación al artículo 269 del CP atenta contra el principio de legalidad en materia penal en cuanto establece nuevas figuras penales que constituyen verdaderos tipos penales en blanco. Señalan que hacer punible la participación por el sólo hecho que de ellos se produzcan los resultados enumerados en el nuevo artículo 269 propuesto por el proyecto de ley, supone consagrar un tipo penal en blanco que contraviene el tercer numeral del artículo 19 de la Constitución, y lo mismo cabe señalar respecto de la agravante del artículo $269 \mathrm{~B}^{12}$.

A su vez, el boletín 8223-25, en la misma línea que el anteriormente citado, considera como un delito contra el orden público la interrupción ilegítima del tránsito, boletín que constituye un tipo penal abierto por su redacción, esto porque la ilegitimidad de la

12. Oficio $\mathrm{N}^{\mathrm{o}} 78 / 2012$, Corte Suprema, Informe proyecto de ley $7975-25$, Santiago de Chile, 27 de Julio de 2012. Pág. 8.

Revista de Ciencias Sociales - Número 62 (2013) - Universidad de Valparáíso - ISSN 0716-7725-Valparaíso, Chile 
interrupción radica si ésta se encuentra autorizada o no por la Intendencia, cuando se trata del ejercicio de reunión pacífica en espacios públicos. En relación a ello, la irrupción ilegítima del tránsito es considerada una conducta antijurídica, sin embargo, esta conducta calificada como un delito contra el orden público no exige que de la interrupción se sigan desórdenes ni que éstos sean graves, tampoco exige la intención de ofender al orden público, que es el bien jurídico que, por su ubicación sistemática, se quiere proteger, sino que sólo exige que esta interrupción pretenda solicitar coactivamente una prestación de cualquier naturaleza. Como es dable observar, los términos "forma coactiva" y "cualquier prestación" permiten que manifestaciones sociales, políticas, laborales u otros actos de presión en sí se consideren un delito contra el orden público.

Por regla general, las manifestaciones sociales se caracterizan por utilizar vías no institucionales a través mecanismos de presión como el paro, huelga, marcha, entre otros, para solicitar alguna prestación o cumplimiento de alguna obligación, que incluso, puede que ni siquiera sea contraria a derecho. Por ejemplo: cuando el sector público se paraliza por ajuste salarial, no se podría señalar que el solicitar aumento de salario es una pretensión antijurídica, sin perjuicio de que las paralizaciones del sector público o las huelgas ilegales se encuentran tipificadas en el artículo 11 de la ley de seguridad del estado (ley número 12.927). Luego, la retipificación del delito de desórdenes públicos y el delito de interrupción del tránsito son inconstitucionales ya que vulneran abiertamente el principio de tipicidad penal consagrado en el artículo 19 número 3 inciso $7^{\circ}$ y $8^{\circ}$ de la CPR.

Ahora bien ¿qué ocurre con el principio de ofensividad o lesividad ("nullum crimen, nulla poena sine iniuria")? Este principio ha sido reconocido por algunos autores como parte del principio de legalidad, resguardado en artículo $19 \mathrm{~N}^{\circ} 3$ inciso final de la CPR, artículo 7.2 de la CADH y artículo 9.1 del PIDCP. Stuart Mill en su obra "Sobre la libertad", reconoce este principio en un aspecto amplio como limitante del poder estatal e incluso de la sociedad en relación a la libertad del individuo, señalando que "el único fin por el cual es justificable que la humanidad, individual o colectivamente, se entremeta en la libertad de acción de uno cualquiera de sus miembros es la

Facultad de Derecho y Ciencias Sociales - Universidad de Valparaíso - Chile 
protección"13. La protección se refiere a la de los demás miembros de la sociedad, la acción de aquél individuo debe significar un perjuicio significativo a otro u otros, de manera que si no existe perjuicio o lesividad, no puede haber limitación en la esfera de la libertad privada de la persona.

Jorge Mera señala que sólo cuando se conoce el bien jurídico protegido por el tipo penal se puede conocer el contenido específico y el alcance efectivo del mismo, por ello, si no hay bien jurídico no se cumple el principio de legalidad; de lo contrario, se podría llegar a la arbitrariedad por parte del poder estatal de tipificar como delito cualquier conducta aun cuando no lesione ni ponga en peligro concreto algún bien jurídico de relevancia, lo que naturalmente no se condice con una sociedad democrática ${ }^{14}$. En este mismo sentido, Ferrajoli indica que si bien el principio de ofensividad no se encuentra directamente consagrado, sería ilógico pensar que un derecho fundamental pueda ser privado por la ley sin que se justifique un acto que ha puesto en peligro o ha lesionado otros derechos fundamentales consagrados en la Constitución o instrumentos internacionales de derechos humanos ${ }^{15}$.

En cuanto al alcance del concepto de ley que se encuentra en la $\mathrm{CADH}$, en la aplicación como instrumento que legitima la privación o restricción de derechos fundamentales reconocidos en ella, la Corte Interamericana de Derechos Humanos (en adelante "Corte IDH”), en la opinión consultiva OC-6/86 del 9 de mayo de 1986 sobre la expresión "leyes" del artículo 30 de la $\mathrm{CADH}$, solicitada por el gobierno de la República Oriental de Uruguay, ha indicado que esta expresión "ley"

13. MILL, Stuart: Sobre la libertad, Alianza, Madrid, 1999. Pág. 68.

14. MERA, Jorge: "Adecuación del derecho penal chileno a las exigencias de los derechos humanos”. En: Medina, Cecilia: Sistema jurídico y derechos humanos, 6. Sociedad de Ediciones de la Universidad Diego Portales, Santiago de Chile, 1996. Págs. 429-437.

15. FERRAJOLI, Luigi: "Derecho penal mínimo y bienes jurídicos fundamentales". En: Revista de la Asociación de Ciencias Penales de Costa Rica, Facultad de Derecho, Universidad de Costa Rica, Año 4, No 5 . Marzo-junio de 1992. (Traducción del profesor Walter Antillón). Pág. 6.

Revista de Ciencias Sociales - Número 62 (2013) - Universidad de Valparáíso - ISSN 0716-7725-Valparaíso, Chile 
debe relacionarse con el principio de legalidad y reserva de ley y, para que constituyan una garantía efectiva de las libertades y derechos, no basta sólo su proclamación formal, sino que debe existir un régimen que garantice eficazmente su aplicación y un control adecuado del ejercicio de las competencias de los órganos ${ }^{16}$. La Corte IDH, para ejemplificar el alcance de la expresión ley en relación al principio de legalidad, cita el artículo 4 de la Declaración de los Derechos del Hombre y del Ciudadano del año 1789, el cual señala que "La libertad consiste en poder hacer todo lo que no perjudica a otro; así, el ejercicio de los derechos naturales de cada hombre no tiene otros límites que los que garantizan a los demás miembros de la sociedad el goce de esos mismos derechos. Estos límites sólo pueden ser determinados por la Ley” ${ }^{17}$. Es decir, para que se restrinja un derecho fundamental esta restricción debe ser por ley, pero el fundamento mismo de aquella sólo se justifica por la lesión de otro derecho fundamental.

Continúa su análisis señalando que la sola determinación del poder público no basta para restringir los derechos fundamentales, ya que la expresión "ley" se considera como una exigencia de la necesaria limitación a la interferencia del poder público en la esfera de los derechos y libertades de la persona humana. Por ello, la limitación legal debe darse además "por razones de interés general y con el propósito para el cual han sido establecidas" 18 .

Parece evidente que el solo hecho de cubrirse el rostro, como se tipifica en el boletín 7155-25, no afecta ningún bien jurídico, ni siquiera podría argumentarse que el bien afectado sería la correcta administración de justicia, ya que es deber del ministerio público y de la policía el investigar los hechos delictivos; nadie tiene el deber de autoincriminarse lo que deriva del principio de presunción de inocencia y finalmente, sería ilógico establecer una agravante específica, ya que, tal como señala Mañalich, no habría diferencia con exigir que quien

16. Considerando 24, Opinión consultiva 6/86, Corte Interamericana de Derechos Humanos, págs. 6-7, (1986).

17. Ídem.

18. Ibídem. Considerando 27.

Facultad de Derecho y Ciencias Sociales - Universidad de Valparaíso - Chile 
roba debe hacerlo sin guantes con el fin de no impedir la identificación mediante huellas al investigador ${ }^{19}$.

\section{Responsabilidad individual de las penas y el derecho a no autoincriminarse}

Las garantías de la responsabilidad individual de las penas y el derecho a no autoincriminarse se relacionan con el principio de culpabilidad. La culpabilidad, en palabras de Náquira, es un juicio de reproche, eminentemente personal, que la sociedad formula al autor de una conducta típica y antijurídica, porque en la situación concreta respectiva, el sujeto podría haber evitado la perpetración de la conducta ilícita y de esta forma haber actuado conforme a derecho, pero no lo hizo $^{20}$. Así, el principio de personalidad de la sanción penal es una consecuencia del principio de culpabilidad ${ }^{21}$ y el derecho a no autoincriminarse es manifestación de la presunción de inocencia.

El principio de personalidad de las penas se encuentra consagrado en el artículo 5.3 de la CADH y señala que la pena no puede trascender de la persona del delincuente, es decir, la responsabilidad penal es personalísima, no pudiendo responderse por el hecho ajeno. El principio de presunción de inocencia se encuentra consagrado constitucionalmente en el artículo 19 número 3 inciso $6^{\circ}$ que prescribe que la ley no puede presumir de derecho la responsabilidad penal y en el artículo 14.2 del PIDCP, debiendo demostrar el Ministerio Público o el querellante la culpabilidad de la persona que es acusada de haber cometido un acto típico y antijurídico.

A su turno, el derecho a no autoincriminarse es un corolario de la presunción de inocencia y se encuentra consagrado en el artículo 8.2 letra g) ${ }^{22}$ de la CADH y en el artículo 14.3 letra g) ${ }^{23}$ del PIDCP, por lo

19. Actas Comisión Seguridad Ciudadana y Drogas. Sesión No 56, 9 de noviembre de 2011. Pág. 3.

20. NÁQUIRA, Jaime et al: ob. cit. Pág. 13.

21. Ibídem. Pág. 14.

22. Toda persona inculpada de delito tiene derecho a que se presuma su inocencia mientras no se establezca legalmente su culpabilidad. Durante el proceso,

Revista de Ciencias Sociales - Número 62 (2013) - Universidad de Valparáíso - ISSN 0716-7725-Valparáiso, Chile 
tanto, en virtud del artículo 5 inciso $2^{\circ}$ de la $\mathrm{CPR}^{24}$, estas disposiciones tienen rango constitucional ${ }^{25} \mathrm{y}$ ambas señalan que durante el proceso toda persona tiene derecho a no ser obligado a declarar contra sí mismo ni a declararse culpable, descartando de esta forma la posibilidad al legislador de castigar penalmente el autoencubrimiento. Sin embargo, y frente a todas las consagraciones constitucionales e internacionales, la tendencia legislativa, mediante los boletines 7155-25 y 7975-25 vulneran el principio de personalidad de las penas y el derecho a no autoincriminarse.

En primer lugar, el boletín 7975-25 castiga con la pena de autor (541 días a 3 años) a los fomentadores, incitadores o promovedores de hechos que sobrevinieron en desórdenes u otros actos de fuerza o violencia, con tal de que hayan podido preverlos. En este sentido basta que una manifestación haya sido convocada para ejercer el derecho de reunión en forma pacífica y en el transcurso de la misma se transforme en una manifestación violenta, para hacer responsable al convocante de un hecho que ni siquiera cometió. Este boletín es muy ilustrativo de cómo se hace responder penalmente a una persona por hechos ajenos, no es necesario para que el convocante responda, la participación en los desórdenes, ni mucho menos (porque el tipo penal no lo pide) el ánimo de alterar el orden público, tampoco es necesario para que

toda persona tiene derecho, en plena igualdad, a las siguientes garantías mínimas: g) derecho a no ser obligado a declarar contra sí mismo ni a declararse culpable.

23. Durante el proceso, toda persona acusada de un delito tendrá derecho, en plena igualdad, a las siguientes garantías mínimas: g) A no ser obligada a declarar contra sí misma ni a confesarse culpable.

24. El ejercicio de la soberanía reconoce como limitación el respeto a los derechos esenciales que emanan de la naturaleza humana. Es deber de los órganos del Estado respetar y promover tales derechos, garantizados por esta Constitución, así como por los tratados internacionales ratificados por Chile y que se encuentren vigentes.

25. MEDINA, Cecilia: "Los derechos humanos contenidos en tratados: su jerarquía y otros problemas relativos a la enmienda del artículo $5^{\circ}$, inciso $2^{\circ}$, de la Constitución chilena”. En: Medina, Cecilia: Sistema jurídico y derechos humanos, 6. Sociedad de Ediciones de la Universidad Diego Portales, Santiago de Chile, 1996. Págs. 64-69.

Facultad de Derecho y Ciencias Sociales - Universidad de Valparaíso - Chile 
responda que la tranquilidad pública sea alterada gravemente, puede ser una alteración insignificante, sino que basta que haya podido prever, no querer, que la manifestación pudiese terminar en desórdenes de cualquier entidad y naturaleza.

Asimismo, el boletín 7155-25, tipifica como delito autónomo el intervenir con el rostro cubierto en un acto público, autorizado o no. No es necesario para configurar el tipo penal el intervenir en desórdenes, no se específica lo qué es intervenir en acto público, sino que basta intervenir encapuchado en un acto público, autorizado o no. El bien jurídico directamente vulnerado es el principio de ofensividad, como lo vimos anteriormente, por la inexistencia de un bien jurídico asociado al ilícito y de manera secundaria, podría verse afectado el derecho a no autoincriminarse, porque el mismo proyecto contempla una regla de concurso real en caso de haber cometido otro delito estando encapuchado, por lo tanto, se estaría imponiendo a la persona el deber de delinquir a rostro descubierto para facilitar la labor investigativa del Estado.

El boletín 7975-25 incorpora en su artículo 269 bis b, una agravante específica para los delitos contra la autoridad y los desórdenes públicos, que es el participar en desórdenes o en cualquier acto de fuerza o violencia encapuchado o con el rostro cubierto. Éste vulnera el derecho a no autoincriminarse y se presta para dudas el establecimiento de una agravante específica para un delito —que incluso puede dañar insignificantemente el orden público-, ya que en materia de delitos contra la autoridad y el orden público, se vuelve sumamente necesario, según el ejecutivo, la incorporación de esta agravante para castigar a los encapuchados, infiriendo que el bien jurídico afectado sería la administración de justicia, siendo obstruido por la persona al utilizar capucha o vestimentas que cubran su rostro, dificultando la investigación del Estado. Sin embargo, ello no tiene mayor sustento pues supone que es lo mismo exigirles a los que roban que delincan sin pasamontañas o sin guantes, porque la utilización de estos accesorios retarda y dificulta la persecución penal, siendo un deber del ciudadano el delinquir a rostro cubierto, como una verdadera carga pública. Esta pretendida exigencia no tiene verdadera legitimidad, justamente porque se entiende que las personas buscan cubrir sus errores y que el

Revista de Ciencias Sociales - Número 62 (2013) - Universidad de Valparáíso - ISSN 0716-7725-Valparaíso, Chile 
autoencubrimiento es algo natural, es por ello que este derecho tiene consagración en los instrumentos internacionales mencionados.

\section{Garantía de protección judicial}

La garantía de protección judicial se encuentra consagrada en el artículo 25 de la CADH que consagra el "derecho de todo individuo a un recurso sencillo y rápido o a cualquier otro recurso efectivo ante los jueces o tribunales competentes, que la ampare contra actos que violen sus derechos fundamentales reconocidos por la Constitución, la ley o la Convención Americana...”. Los Estados se comprometen a garantizar el principio de inexcusabilidad, a desarrollar las posibilidades de un recurso judicial y a garantizar el cumplimiento de toda decisión en que se haya estimado procedente el recurso.

El boletín 7895-25 que modifica el artículo 85 que regula el procedimiento sobre control de identidad, entre una de sus propuestas de reforma elimina la referencia actual del CPP "que el procedimiento dirigido a obtener la identidad de una persona, debe realizarse en la forma más expedita posible, y el abuso en su ejercicio podrá ser constitutivo del delito previsto y sancionado en el artículo 255 del Código Penal". Este artículo sanciona con la suspensión de empleo y multa al funcionario público que estando en servicio cometiere cualquier vejación injusta contra las personas o usare de apremios ilegítimos o innecesarios.

La remisión actual del artículo 85 cumpliría con el parámetro del artículo 25.1 de la $\mathrm{CADH}$, porque permitiría al particular que sufre un abuso en este procedimiento, realizar una denuncia o querellarse por vejación injusta, siendo el abuso el hecho constitutivo de la misma, lo que permite la existencia de un recurso expedito y sencillo. Al eliminar esta referencia, el particular tendría que probar que ese abuso policial constituye vejación injusta, lo que ya es un término amplio; además, la interpretación armónica del mismo artículo nos lleva a concluir que existe un criterio en cuanto a la gravedad de los hechos, equiparando la vejación injusta con los apremios ilegítimos, lo que es un estándar probatorio bastante alto.

Facultad de Derecho y Ciencias Sociales - Universidad de Valparaíso - Chile 
Por último, si se elimina, el delito cometido por el funcionario público en ejercicio de sus funciones podría interpretarse a la luz del Código de Justicia Militar, considerándose delito militar y no delito común, como lo es actualmente.

\section{Libertad personal y seguridad individual}

El boletín 7895-25, sobre control de identidad, compromete el derecho reconocido en el artículo 19 número 7 letra c) de la CPR, artículo 7.2 de la CADH y 9.2 del PIDCP, ya que viene a incorporar una nueva causal de detención, el estar encapuchado, que en nuestra legislación vigente no existe como delito ni como falta penal. Esta causal la contemplaba el antiguo artículo 260 del Código de Procedimiento Penal, en su numeral $3^{\circ}$, siendo esta disposición muy criticada por ser contraria a la Constitución Política ${ }^{26}$. Fue modificada por la ley número 19. 567 del año 1998 que tuvo como finalidad, entre otras, terminar con la llamada "detención por sospecha" y dar cumplimiento al mandato constitucional en cuanto a la protección de los derechos fundamentales de las personas, contemplado en el artículo 5 de la $\mathrm{CPR}^{27}$. Sin embargo, se intenta volver a crear la detención por sospecha, ahora ya no regulada en las causales propias de detención, sino que camuflada entre las causales de detención en relación al control de identidad.

Nuestra Constitución, en el artículo 19 número 7 letra c) ${ }^{28}$, conforme al espíritu de las normas de derecho internacional antes citadas, permite detener a una persona sólo por orden judicial previa o

26. RIEGO, Cristian: "El sistema procesal penal chileno frente a las normas internacionales de derechos humanos”. En: Medina, Cecilia: Sistema jurídico y derechos humanos, 6. Sociedad de Ediciones de la Universidad Diego Portales, Santiago de Chile, 1996. Pág. 281.

27. Historia de la ley $\mathrm{N}^{\circ}$ 19. 567. Diario Oficial de 01 de Julio de 1998. Pág. 10.

28. Nadie puede ser arrestado o detenido sino por orden de funcionario público expresamente facultado por la ley y después de que dicha orden le sea intimada en forma legal. Sin embargo, podrá ser detenido el que fuere sorprendido en delito flagrante, con el solo objeto de ser puesto a disposición del juez competente dentro de las veinticuatro horas siguientes.

Revista de Ciencias Sociales - Número 62 (2013) - Universidad de Valparáíso - ISSN 0716-7725-Valparáiso, Chile 
por delito flagrante. Una excepción a las causales de detención se encuentra en el artículo 134 del CPP que hace procedente la detención en caso que se encuentre consumada la falta flagrante del artículo 496 número 5, la que se constituye al negarse la persona a acreditar su identidad cuando es solicitada por funcionario competente, aun así ello no implica detener a una persona por el sólo hecho de usar disfraz u otro medio de ocultamiento de su identidad. Este proyecto también afectaría la libertad personal en cuanto modifica la obligación de las policías a solicitar la identificación de una persona según respecto a cuatro casos nombrados taxativamente en el artículo, por una facultad para exigirla en casos fundados que se nombran a modo ejemplar utilizando la expresión "tales como", volviendo a la antigua redacción de este artículo antes de la reforma de la ley número 20.253 del año 2008.

La reforma que llevó a cabo la ley número 20.253 tuvo como propósito revertir el control judicial de las detenciones efectuadas con ocasión del control de identidad, ya que en la práctica los jueces de garantía exigían al funcionario público el probar la existencia de tales indicios, los que se interpretaban de forma taxativa, a pesar de que el artículo empleaba la expresión "tales como" 29 . Lo que hace este proyecto es ampliar las causales que autorizan el control de identidad, utilizando la expresión "tales como", volviendo a la categoría ejemplar mencionada por el Código de Procedimiento Penal antes de la reforma de la ley número 20.253, abriendo paso a la arbitrariedad e incertidumbre frente a este procedimiento en que las policías puedan considerar como casos fundados otros que no se explicitan en el artículo, razón que creemos que fue la causa por lo que los jueces de garantía forzaron la interpretación de ese antiguo artículo, restringiendo las hipótesis que permitían el control de identidad, a modo de hacerlo más ajustado a la protección de las garantías fundamentales de las personas frente a casos abusivos y posibles detenciones con ocasión de dicho procedimiento, de manera que no pudiera confundirse su finalidad al de un instrumento propio para llegar a una detención sin necesidad de un delito flagrante ${ }^{30}$.

29. Historia de la ley $N^{\circ}$ 20.253. Diario Oficial de 14 de Marzo de 2008. Pág. 73.

30. RAMOS, César: "Control de identidad. Bases para una aplicación diferenciada del artículo 85 del Código procesal penal”. En: Fuentes, Claudio: Diez años de la reforma procesal penal en Chile. Sociedad de Ediciones, Universidad Diego Portales, Santiago de Chile. 2011. Págs. 589-590.

Facultad de Derecho y Ciencias Sociales - Universidad de Valparaíso - Chile 


\section{Libertad de conciencia y no discriminación arbitraria}

Ejemplificamos la situación en la que se encontrarían aquellas personas que por su culto, religión o creencia personal, cubran su rostro habitualmente al transitar en los espacios públicos o privados, como lo hacen las mujeres musulmanas. El boletín $\mathrm{N}^{\circ}$ 7155-25, al tipificar como delito el participar, con el rostro cubierto, en un acto público autorizado o no, podría vulnerar la libertad de conciencia, la que se encuentra consagrada en el artículo 19 número 6 inciso $1^{\circ}$ de la $\mathrm{CPR}^{31}$, en el artículo 12 número 1,2 y 3 de la $\mathrm{CADH}^{32}$ y artículo 18 número 1 y 3 del PIDCP ${ }^{33}$. Este derecho incluye la libertad de manifestar su religión o creencia, individual o colectivamente, tanto en público como en privado, mediante el culto, la celebración de los ritos, las prácticas y la enseñanza. Dentro de las prácticas de una determinada religión o creencia nos encontramos con la de cubrirse el rostro, tal como lo ha señalado

31. Derecho a la libertad de conciencia, la manifestación de todas las creencias y el ejercicio libre de todos los cultos que no se opongan a la moral, a las buenas costumbres o al orden público.

32. 1. Toda persona tiene derecho a la libertad de conciencia y de religión. Este derecho implica la libertad de conservar su religión o sus creencias, o de cambiar de religión o de creencias, así como la libertad de profesar y divulgar su religión o sus creencias, individual o colectivamente, tanto en público como en privado. 2. Nadie puede ser objeto de medidas restrictivas que puedan menoscabar la libertad de conservar su religión o sus creencias o de cambiar de religión o de creencias. 3. La libertad de manifestar la propia religión y las propias creencias está sujeta únicamente a las limitaciones prescritas por la ley y que sean necesarias para proteger la seguridad, el orden, la salud o la moral públicos o los derechos o libertades de los demás.

33. 1. Toda persona tiene derecho a la libertad de pensamiento, de conciencia y de religión; este derecho incluye la libertad de tener o de adoptar la religión o las creencias de su elección, así como la libertad de manifestar su religión o sus creencias, individual o colectivamente, tanto en público como en privado, mediante el culto, la celebración de los ritos, las prácticas y la enseñanza. 3. La libertad de manifestar la propia religión o las propias creencias estará sujeta únicamente a las limitaciones prescritas por la ley que sean necesarias para proteger la seguridad, el orden, la salud o la moral públicos, o los derechos y libertades fundamentales de los demás.

Revista de Ciencias Sociales - Número 62 (2013) - Universidad de Valparáíso - ISSN 0716-7725-Valparáiso, Chile 
expresamente el Comité de Derechos Humanos, en cuanto a que tales prácticas que se mencionan en el Pacto pueden ilustrarse en costumbres como "la observancia de normas dietéticas, el uso de prendas de vestir o tocados distintivos, la participación en ritos asociados con determinadas etapas de la vida, y el empleo de un lenguaje especial que sólo hablan los miembro del grupo" ${ }^{34}$.

Si tipificamos como delito el cubrirse el rostro en un acto público, sin ningún requisito que exija ofender otro bien jurídico, sin que exista una causal de justificación específica que permita que una persona en ejercicio de un culto se pueda eximir de responsabilidad penal, y sin distinguir las motivaciones de este hecho, podría eventualmente, en caso de detención y condena, vulnerar tanto el derecho a la libertad de culto, ya que el ejercicio de este derecho, al cubrirse el rostro, no se considera dentro de las causales de justificación (artículo 10 del CP), y podría vulnerar la igualdad ante la ley, consagrado en el artículo 19 número 2 de la CPR, en el artículo 24 de la CADH y en los artículos 26 y 27 del PIDCP, el que prohíbe toda discriminación arbitraria, ya que el hecho que genera responsabilidad penal no hace distinción en la motivación del mismo.

\section{Libertad de expresión y opinión}

Derecho reconocido en el artículo 12 de la CPR que consagra en su inciso primero el derecho a "la libertad de emitir opinión y la de informar, sin censura previa, en cualquier forma y por cualquier medio, sin perjuicio de responder de los delitos y abusos que se cometan en el ejercicio de estas libertades, en conformidad a la ley, la que deberá ser de quórum calificado", en el artículo 13 de la $\mathrm{CADH}^{35}$ y en el artículo

34. GONZÁLEZ, Felipe: "El sistema procesal penal chileno frente a las normas internacionales de derechos humanos". En: Medina, Cecilia: Sistema jurídico $y$ derechos humanos, 6. Sociedad de Ediciones de la Universidad Diego Portales, Santiago de Chile, 1996. Pág. 129.

35. 1. Toda persona tiene derecho a la libertad de pensamiento y de expresión. Este derecho comprende la libertad de buscar, recibir y difundir informaciones e ideas de toda índole, sin consideración de fronteras, ya sea oralmente, por escrito o en forma impresa o artística, o por cualquier otro procedimiento de su elección (...).

Facultad de Derecho y Ciencias Sociales - Universidad de Valparaíso - Chile 
19 del PIDCP ${ }^{36}$. Se podría vulnerar este derecho, en el ejemplo de la mujer musulmana de acuerdo al boletín 7155-25, al impedirle intervenir en un acto público autorizado o no, por ejemplo, un discurso en una concentración autorizada en una plaza, ya que si lo hace, estará cometiendo un delito por llevar cubierto su rostro, aun sin cometer otro ilícito. Las circunstancias generales contempladas en el CP que permiten eximirse o atenuar la responsabilidad penal tampoco dan cabida a la situación predicha.

De acuerdo al boletín No 7155-25, se puede dar el caso hipotético de que una persona, dentro del contexto de un acto público autorizado o no, cubra su rostro como una forma de expresión artística utilizada como medio para emitir su opinión o difundir información. Por ejemplo, pinte su cuerpo y use una máscara. Los artículos 12 de la CPR, 13 de la CADH y artículo 19 del PIDCP reconocen el derecho a expresarse, en cualquier forma y por cualquier medio, sin perjuicio de responder por los delitos y abusos que se cometan en el ejercicio de este derecho. El artículo 19 del PIDCP reconoce explícitamente que la forma de expresión puede ser la artística, y nuestra Constitución contiene en el artículo 19 número 25 un reconocimiento especial a la libertad de crear y difundir las artes. El proyecto de ley, al no exigir ningún otro requisito que el de cubrir el rostro en un acto público, autorizado o no, para tipificarlo como delito, podría criminalizar las manifestaciones artísticas de quienes se expresan cubriendo su rostro de alguna forma. Incluso, el proyecto señala que la conducta ilícita consiste en cubrir el rostro de manera que se impida identificar a la persona por registros fotográficos, cinematográficos o videos; por lo que cabe dentro del margen de conducta ilícita cualquier forma de cubrir el rostro que impida reconocer la identidad de la persona, incluyendo el maquillaje, como por ejemplo, el de un payaso o un mimo.

La libertad de creación artística consagrada en nuestra constitución es una forma particular de reconocimiento de la libertad

36. (...) 2. Toda persona tiene derecho a la libertad de expresión; este derecho comprende la libertad de buscar, recibir y difundir informaciones e ideas de toda índole, sin consideración de fronteras, ya sea oralmente, por escrito o en forma impresa o artística, o por cualquier otro procedimiento de su elección (...).

Revista de Ciencias Sociales - Número 62 (2013) - Universidad de Valparáíso - ISSN 0716-7725-Valparaíso, Chile 
de expresión y puede verse vulnerada por el temor de los artistas a recibir una sanción, debiendo las limitaciones impuestas por ley responder a una ponderación de valores y derechos constitucionales ${ }^{37}$. Esta regla rige para todas las garantías fundamentales, no obstante, en este proyecto de ley no encontramos valor o derecho alguno que ponderar con esta restricción, ya que, como se señaló precedentemente, no existe bien jurídico que proteger. Esta libertad se constituye de dos fundamentos: la creación y la difusión de esa creación. Los medios para la creación pueden ser cualquiera, en nuestro ejemplo tenemos las pinturas o elementos para confeccionar la máscara, y en cuanto a la difusión los medios también pueden ser variados, incluyendo aquél en que el medio es el mensaje $\mathrm{e}^{38}$. Por ejemplo, la máscara misma por sí sola puede representar una obra de arte, pero de acuerdo al mensaje que quiere dar el artista con la máscara creada sólo podría realmente concretarse como obra en cuanto sea usada por una persona en el contexto de una marcha estudiantil, como ejemplo de acto público autorizado.

Finalmente, este derecho lo relacionamos con aquél consagrado en el artículo 15.1 del Pacto Internacional de Derechos económicos, sociales y culturales, en adelante "PIDESC", que reconoce el derecho que tiene toda persona de gozar de la vida cultural en una nación y con el reconocimiento en nuestra constitución en el artículo 1 inciso 4, en cuanto a que el Estado debe velar por la mayor realización espiritual de las personas, siendo el arte un elemento de nuestra espiritualidad.

\section{Libertad de expresión y protesta social}

Como expresamente lo señalan informes de organismos de derechos humanos y estudios doctrinales sobre la manifestación o protesta social, ésta implica el ejercicio conjunto de tres derechos fundamentales: la libertad de expresión, la libertad de reunión y la libertad de asociación. Asimismo, la Corte IDH, se ha referido a la

37. VIAL, Tomás: "El derecho a la libertad de creación artística en la Constitución”. En: González, Felipe: Libertad de expresión en Chile. Facultad de Derecho de la Universidad Diego Portales, Santiago de Chile, 2006. Pág. 266.

38. Ibídem, pág. 269.

Facultad de Derecho y Ciencias Sociales - Universidad de Valparaíso - Chile 
funcionalidad de la libertad de expresión "como crítica, poder de denuncia o exigencia individual o colectiva" ${ }^{39}$, lo que rápidamente podemos asociar a la protesta social o manifestaciones callejeras. Por ende, podemos afirmar que el ejercicio del derecho a la manifestación, por cualquier medio, incluyendo la manifestación callejera, lleva implícito el derecho a la libertad de expresión. Pues bien, nos encontramos que desde el momento en que se pretende legislar sobre conductas y sus consecuencias penales en un contexto de protesta social, cuya normativa va dirigida a ciertos manifestantes que incurran en estas conductas tipificadas, estamos, en un principio, restringiendo la libertad de expresión. Sin embargo, tal como lo señala la jurisprudencia y doctrina y las mismas cartas que los reconocen, los derechos fundamentales no son absolutos y, en cuanto a la libertad de expresión, puede limitarse debido a razones de vulneración de otros derechos o libertades, en resguardo de la seguridad nacional, de la salubridad o moralidad pública y del orden público (Artículos 13.2 CADH y 19.3 PIDCP).

En los proyectos en comento, la justificación para restringir la libertad de expresión la encontramos en los derechos y libertades de otros, por ejemplo, como el derecho de propiedad e inclusive el derecho a manifestarse de forma pacífica, pero desde una mirada más amplia vemos que la justificación última de todos ellos es el orden público. El orden público, en principio, es un justificante de la limitación de la libertad de expresión y opinión, sin embargo, no basta sólo invocar al orden público como razón para restringirla, sino que además es necesario revisar si esta restricción cumple con los demás requisitos señalados en la CADH y en la jurisprudencia de la Corte IDH, de forma que la limitación de este derecho sea legítima ${ }^{40}$.

39. Caso Ulloa v/s Costa Rica, Voto concurrente del Juez Sergio García Ramírez, Sentencia Corte Interamericana de Derechos Humanos, Costa Rica, 02 de Julio de 2004. Pág. 3.

40. Opinión Consultiva OC-5/85, Corte Interamericana de Derechos Humanos, 1985. Pág. 20.

Revista de Ciencias Sociales - Número 62 (2013) - Universidad de Valparáíso - ISSN 0716-7725-Valparaíso, Chile 


\section{Requisitos para la limitación legítima de derechos fundamentales}

La limitación (restricción o privación) a los derechos fundamentales es inherente a los proyectos de ley que expanden al derecho penal, ya sea creando nuevas figuras delictivas o aumentando las penas asociadas a delitos ya existentes, característica que comparten los proyectos de ley analizados. Luego de haber analizado los posibles derechos fundamentales comprometidos, es necesario observar si la limitación a éstos cumple con los requisitos que ha impuesto la jurisprudencia internacional en materia de derechos fundamentales para que esta limitación sea legítima.

De los distintos fallos de la Corte IDH (Herrera Ulloa vs Costa Rica, 2004; Baena Ricardo y otros vs Panamá, 2001; Usón Ramírez vs Venezuela, 2009; Perozo y otros vs Venezuela, 2009; Kimel vs Argentina, 2008; Opinión consultiva OC-5/1985, 1985) y de la jurisprudencia de la Corte Europea de Derecho Humanos ${ }^{41}$, podemos señalar que las restricciones a la libertad de expresión y al derecho a reunión únicamente se encuentran justificadas cuando: se encuentran establecidas por ley; debe tratarse de un interés público de carácter imperativo (el objetivo debe ser proteger la seguridad nacional, la seguridad pública, la defensa del orden, la prevención del delito, la protección de la salud, de la moral o la protección de los derechos y libertades ajenas); siempre y cuando se trate de restricciones necesarias en una sociedad democrática (la limitación debe ser conducente, proporcional y necesaria) y la opción penal debe dejarse como última medida, ya que ésta es la herramienta más severa con que cuenta el Estado para sancionar.

A pesar de que estas limitaciones se confeccionan a propósito de la libertad de expresión y el derecho a reunión, se ha extrapolado este razonamiento y estos parámetros a la restricción de todos los derechos fundamentales y, particularmente, en materia penal, estos requisitos constituyen parte del contenido del principio de proporcionalidad en sentido amplio, agregándose un requisito en materia penal: la proporción entre la gravedad de los hechos y el monto de la sanción ${ }^{42}$.

41. Informe anual sobre Derechos Humanos en Chile 2008, Universidad Diego Portales. Pág. 50.

42. MERA, Jorge: Derechos Humanos en el Derecho Penal Chileno. LexisNexis, Santiago de Chile, 2006. Págs. 94-97.

Facultad de Derecho y Ciencias Sociales - Universidad de Valparaíso - Chile 
Este cuarto requisito es conocido también como "principio de proporcionalidad en sentido estricto". Como estas exigencias constituyen un parámetro para evaluar la legitimidad de la limitación de todo derecho fundamental, a continuación revisaremos la adecuación de los proyectos de ley a las exigencias establecidas por la jurisprudencia internacional en materia de derechos humanos.

\subsection{Interés público de carácter imperativo}

Estas restricciones deben darse en cumplimiento de un interés general público de carácter imperativo, esto es, realizar un análisis balanceado de la colisión de intereses involucrados. En la mayoría de los casos estos intereses son: libertad de expresión y los derechos protegidos por el orden público. En cuanto a este requisito, nos encontramos que algunos proyectos carecen de este fundamento. Por ejemplo, aquél que penaliza a quienes participan de desórdenes públicos con el rostro cubierto, ya que el interés de tipificar la conducta de cubrir el rostro está relacionado sólo con facilitar el trabajo de la policía para pesquisar y detener a los autores de los delitos de desórdenes públicos, lo que atentaría al derecho de cualquier persona a manifestarse con el rostro cubierto, es decir, utilizando la vestimenta que desee en el contexto de la manifestación.

En la misma medida, el boletín $\mathrm{N}^{\circ} 7895-25$, que modifica el procedimiento de control de identidad que corresponde realizar a la policía, se fundamenta en el sólo interés de estos funcionarios públicos en no sentirse amenazados por el actual artículo que regula el procedimiento, ya que éste hace una referencia a la sanción penal que tendría el funcionario por actuar más allá de lo reglamentado. El derecho de expresión restringido lo encontramos indirectamente en la práctica abusiva de estos controles de identidad por parte de la policía, ya que se utiliza como una detención por sospecha ejercida principalmente en las manifestaciones callejeras con el fin de impedir que la persona detenida pueda participar de la manifestación.

Revista de Ciencias Sociales - Número 62 (2013) - Universidad de Valparáíso - ISSN 0716-7725-Valparaíso, Chile 


\subsection{Limitación conducente, proporcional y necesaria}

Cualquier limitación debe ser conducente, proporcional y necesaria, es decir, conducente es que permita alcanzar el fin que persigue, que sea proporcional al fin perseguido y necesaria se refiere a que no existe otra alternativa — más que la restricción del derechopara alcanzar el objetivo legítimo. El Boletín $\mathrm{N}^{\circ} 7018-25$, que sanciona con mayor rigor las falsas alarmas públicas, tiene como finalidad evitar la conmoción pública con todas sus consecuencias. En cuanto a la proporcionalidad no está justificada porque este delito no afecta un bien jurídico de mayor jerarquía, como son aquellos bienes personalísimos, sólo afectaría el orden público en su ámbito de tranquilidad pública. En cuanto a si es necesario aumentar la penalidad, consideramos que tampoco cumple este requisito, porque este delito ya cuenta con su respectiva penalidad proporcional al bien jurídico protegido e intentar aumentarla no prevendría su comisión.

A su turno, el boletín $\mathrm{N}^{\circ} 7155-25$, que sanciona a quienes participen en desórdenes públicos con el rostro cubierto, es conducente en cuanto a que el fin que persigue es el de facilitar el trabajo a las policías, sin embargo este fin, como vimos, no cumple con el requisito anterior de interés público imperativo. Si se trata del fin último que es resguardar el orden público, no cumpliría este requisito, ya que el orden público puede ser alterado por personas que cubren su rostro, como también por aquellas que no lo cubran. No es proporcional, ya que detener a personas por el simple hecho de cubrir su rostro no tiene estricta relación con el hecho de poder prevenir desórdenes públicos. No es necesaria, ya que la vía para prevenir desórdenes públicos no se encontraría en el tipificar a personas que cubren su rostro para poder privarlas de libertad por el simple hecho de hacerlo, sino que más bien debe tratarse mediante una política criminal que otorgue los medios adecuados para que no se genere desorden o violencia en las calles.

Por su parte, el boletín $\mathrm{N}^{\circ} 7290-25$, que agrava la responsabilidad penal del que daña cámaras de televigilancia, no es conducente, ya que agravando las penas de los delitos de daños en bienes destinados a implementar los planes de seguridad pública con el fin de obtener la privación de libertad de aquellos que lo cometan, no generará mayor

Facultad de Derecho y Ciencias Sociales - Universidad de Valparaíso - Chile 
seguridad pública, sino que generará más reos en las cárceles. No es proporcional, ya que por mucho que esté comprometida la seguridad de la ciudadanía, no podemos privar de libertad a una persona por dañar un bien que podría llegar a ser insignificante para el efectivo resguardo de la seguridad pública en la realidad, por lo que el tipo penal, para llegar a ser proporcional, debiese tener un circunstancia de peligro concreto. No es necesario, ya que para impedir que se dañen bienes que sirven para proteger la seguridad pública, es suficiente la pena pecuniaria y el reforzamiento y protección material de dichos bienes. El boletín $\mathrm{N}^{\circ} 7895-25$, que modifica el procedimiento de control de identidad, es conducente para el objetivo plasmado en el proyecto, ya que las policías se sentirán más libres para ejercer todos los controles de identidad que estimen convenientes sin temor a ser denunciado por abuso de autoridad. No es proporcional, ya que disminuye de cierta forma la garantía del detenido o retenido de tener certeza sobre los límites del actuar de la policía y la facilidad para denunciar los excesos cometidos por el funcionario. No es necesaria, ya que el resguardo del orden público involucra también que las personas no puedan ser vulneradas en sus derechos por actos arbitrales de las policías, lo que llevaría a una sensación de inseguridad en la ciudadanía debido a las actuaciones de los agentes estatales, lo cual contribuye a abrir una puerta para la vulneración del orden público en su acepción de tranquilidad pública.

El boletín 7975-25, que fortalece el resguardo del orden público, no es conducente, ya que por medio de este proyecto no se fortalecerá el resguardo del orden público, sino que se restringen de forma indirecta derechos fundamentales de las personas, lo que generará (y está generando) descontento social que puede llegar a volverse una reacción violenta frente a una ley que amedrenta el ejercicio de derechos reconocidos, por lo tanto, más bien, hace vulnerable el orden público. No es proporcional, ya que el actual delito de desórdenes públicos contiene los requisitos penales para sancionar a quien lo ejerce, existe la falta de desorden público cuando éste no es grave, y las penas cumplen con el detrimento del bien jurídico protegido, por lo que aumentar la severidad de la pena, del procedimiento y de la tipicidad es ir más lejos de lo estrictamente necesario. No es necesario porque el resguardo del

Revista de Ciencias Sociales - Número 62 (2013) - Universidad de Valparáíso - ISSN 0716-7725-Valparaíso, Chile 
orden público no debe traducirse en la simplista fórmula de aumentar la severidad de la ley como lo hace este proyecto, sino que trata de un plan de política criminal mucho más complejo y a largo plazo, que se basa fundamentalmente en fortalecer la democracia.

Luego, el boletín $\mathrm{N}^{\circ}$ 8223-25, que penaliza la interrupción del tránsito con fines coactivos, es conducente, ya que por esta tipificación se explicita que la detención del tránsito es un delito con pena de privación de libertad, cuestión que no siempre es así de acuerdo a la redacción del actual delito de desórdenes públicos, y así llegaríamos a la certeza de la existencia de un delito que atenta contra el orden público. No es proporcional, ya que el derecho a la libertad de expresión pugna con el derecho de libre circulación y el orden público, y dado que la libertad de expresión es "la piedra angular del estado de derecho" sanción por el ejercicio abusivo de este derecho debiese ser pecuniaria, $\mathrm{u}$ otra pena alternativa, y no privativa de libertad. No es necesaria, ya que puede tipificarse explícitamente como falta, con una pena pecuniaria o con otra no privativa de libertad, conservando los parámetros del artículo 269, en cuanto para llegar a constituir delito de desorden público debe ser grave y debe tener un fin reprochable, y no con la vaguedad en que está redactado el proyecto.

Finalmente, el boletín $\mathrm{N}^{\circ} 8420-25$, que modifica el delito de desórdenes públicos, es conducente ya que modifica el actual artículo 269 del CP para describir las situaciones fácticas que constituyen delito de desorden público, que actualmente en la práctica se están dando en las protestas sociales. No es proporcional, porque faltaría referirse a la gravedad de las consecuencias que se mencionan y el fin reprochable, al igual que en el caso de obstaculizar las vías públicas o invadir inmuebles de propiedad ajena, debe hacerse referencia, tal como lo hace el código español, a la situación de peligro que estos actos pueden afectar a las personas; sin estas limitantes, la restricción a un uso considerado abusivo de la libertad de expresión no puede sancionarse con privación de libertad. Existe otra alternativa, que está dada por los actuales criterios del delito de desórdenes públicos: el fin reprochable y la gravedad, la

43. Caso Perozo y otros v. Venezuela, Sentencia Corte Interamericana de Derechos Humanos, Costa Rica, 28 de Enero de 2009. Pág. 33.

Facultad de Derecho y Ciencias Sociales - Universidad de Valparaíso - Chile 
que puede ponderarse mediante la jerarquía de los bienes jurídicos afectados y su extensión. Así, si no se cumple con esa gravedad y fin reprochable, es mejor sancionar sólo con pena pecuniaria u otra que no sea privación de libertad.

\subsection{Derecho penal mínimo}

Todos los proyectos de ley analizados establecen sanciones privativas de libertad o aumento de aquellas penas ya existentes, sin una proporcionalidad entre la sanción, el bien jurídico protegido y las circunstancias que rodean el acometimiento del supuesto hecho ilícito, infringiendo así la exigencia del derecho penal como ultima ratio. Por todo lo anterior, se puede estimar que la tendencia legislativa penal en materia de orden público es inconstitucional ya que en abstracto puede vulnerar tanto el mandato constitucional de determinación o taxatividad, conocido como principio de tipicidad, mediante la creación de tipos penales abiertos y de leyes penales en blanco, vulnera el principio de ofensividad mediante la creación de tipos penales carentes de bienes jurídicos protegidos, infringe disposiciones internacionales con rango constitucional que garantizan la responsabilidad individual de las penas y el derecho a no autoincriminarse estableciendo a los ciudadanos el deber de delinquir con el rostro cubierto, deber que en el evento de no ser cumplido es considerado como un ilícito penal; vulneraría la garantía reconocida internacionalmente de protección judicial al dejar desprovisto de recursos efectivos a los que son controlados en virtud del artículo 85 del CPP; y el castigo del rostro cubierto en todo evento podría llevar a la vulneración de la libertad de conciencia, derecho a no ser discriminado arbitrariamente, libertad de expresión y opinión, manifestación artística y libertad de expresión.

\section{Conclusión}

En Chile, la política criminal de estas últimas décadas se ha caracterizado por una constante expansión del derecho penal, lo que para efectos de esta investigación que se ha enmarcado en el análisis de proyectos de ley referidos al orden público, conlleva al menos dos

Revista de Ciencias Sociales - Número 62 (2013) - Universidad de Valparáíso - ISSN 0716-7725-Valparaíso, Chile 
corolarios: el primero de ellos, la vulneración de determinadas garantías penales consagradas en la Constitución y tratados internacionales ratificados por Chile y que se encuentran actualmente vigentes y; en segundo lugar, que la expansión del derecho penal, no sólo en materia de orden público sino en su aspecto generalizado, trae consigo la inevitable consecuencia de la sobrepoblación carcelaria (y con ello, la vulneración de diversos derechos fundamentales distintos a la libertad ambulatoria, garantizados por los mismos instrumentos jurídicos anteriormente señalados).

La tendencia legislativa penal en materia de orden público, que se ve reflejada en los proyectos de ley analizados correspondientes al período de tiempo que abarca desde el año 2010 a la actualidad, infringe derechos fundamentales garantizados por la Constitución, la Convención Americana de Derechos Humanos, el Pacto Internacional de Derechos Civiles y Políticos, el Pacto Internacional de Derechos Económicos, Sociales y Culturales. Los derechos vulnerados son los siguientes: principio de legalidad (específicamente mediante la vulneración del principio de tipicidad y de ofensividad); la garantía de responsabilidad penal individual de las penas; el derecho a no autoincriminarse; la garantía de protección judicial; libertad personal y seguridad individual; libertad de conciencia y no discriminación arbitraria; libertad de expresión y opinión y manifestación artística. Por tanto, concluimos que los proyectos analizados efectivamente son inconstitucionales, teniendo en cuenta que los instrumentos antes señalados tienen rango constitucional por versar sobre materia de derechos fundamentales, ya que éstos son un límite a la soberanía nacional.

Se ha demostrado que la expansión del derecho penal como política criminal es inconducente para controlar el fenómeno de la criminalidad, sólo genera más delincuencia, mayores índices de reincidencia y sobrepoblación penal ${ }^{44}$, al no considerar los efectos colaterales que la reclusión produce en el interno, es decir, no contempla que el presidio provoca estigmatización social, que las penas largas

44. STIPPEL, Jörg: "Las cárceles y la búsqueda de una política criminal para Chile”. LOM, Santiago de Chile, 2006. Págs. 53-56.

Facultad de Derecho y Ciencias Sociales - Universidad de Valparaíso - Chile 
impiden la resocialización de la persona, el daño patrimonial y moral que afecta a los familiares del recluso y además la vulneración de derechos fundamentales que van más allá de la restricción de la libertad ambulatoria como sanción penal.

En base a lo anterior, concluimos que una de las materias sustanciales y urgentes que debe abordar Chile para poder declararse un verdadero Estado democrático es la de contribuir a terminar con esta tendencia de expansión del derecho penal y para ello, en primer lugar, debe respetar el principio de ofensividad y de ultima ratio, considerando como ilícitos penales sólo aquellos hechos que revistan el carácter de gravedad suficiente para justificar la sanción penal; en segundo lugar, debe contemplar un catálogo más amplio de sanciones penales diferentes a las ya existentes, las que deben ser creadas por el poder legislativo en dirección a aplicar como última medida la privación o restricción de la libertad ambulatoria a los ilícitos penales, es decir, que la sanción asociada pueda ser por ejemplo, el trabajo comunitario, la reparación del mal causado, entre otros.

\section{Bibliografía}

\section{Libros}

GARCÍA, Enrique. La insignificancia en el Derecho Penal, Los delitos de bagatela, Hammurabi, Buenos Aires, 2000.

GARRIDO MONTT, Mario. Derecho penal, parte general, Tomo I, Primera Edición, Editorial Jurídica de Chile, Santiago de Chile, 2001.

GONZÁLEZ, Felipe. “Libertad de conciencia y de religión”. En Sistema jurídico y derechos humanos, 6, Sociedad de Ediciones de la Universidad Diego Portales, Santiago de Chile. 1996.

HORVITZ, María Inés. Derecho procesal penal chileno, Tomo I, Primera Edición, Editorial Jurídica de Chile, Santiago de Chile. 2002.

MILL, Stuart. Sobre la libertad, Alianza, Madrid, 1999.

MEDINA, Cecilia. "Los derechos humanos contenidos en tratados: su jerarquía y otros problemas relativos a la enmienda del artículo

Revista de Ciencias Sociales - Número 62 (2013) - Universidad de Valparáíso - ISSN 0716-7725-Valparaíso, Chile 
$5^{\circ}$, inciso $2^{\circ}$, de la constitución chilena". En: Sistema jurídico y derechos humanos, 6, Sociedad de Ediciones de la Universidad Diego Portales, Santiago de Chile. 1996.

MERA, Jorge. "Adecuación del derecho penal chileno a las exigencias de los derechos humanos". En: Sistema jurídico y derechos humanos, 6, Sociedad de Ediciones de la Universidad Diego Portales, Santiago de Chile. 1996.

MERA, Jorge. Derechos Humanos en el Derecho Penal Chileno, Primera Edición, LexisNexis, Santiago de Chile, 2006.

RAMOS, César: "Control de identidad. Bases para una aplicación diferenciada del artículo 85 del Código procesal penal”. En Diez

años de la reforma procesal penal en Chile, Universidad Diego Portales, Santiago de Chile, 2011.

RIEGO, Cristián. "El sistema procesal penal chileno frente a las normas internacionales de derechos humanos". En: Sistema jurídico y derechos humanos, 6, Sociedad de Ediciones de la Universidad Diego Portales, Santiago de Chile. 1996.

SAINZ CANTERO, José A. Lecciones de derecho penal, parte general, Volumen I, Editorial BOSCH Casa Editorial S.A., Barcelona, 1985.

STIPPEL, Jörg Alfred. Las cárceles y la búsqueda de una política criminal para Chile, LOM, Santiago de Chile, 2006.

VIAL, Tomás. "El derecho a la libertad de creación artística en la constitución”. En: Libertad de expresión en Chile, Publicación

de la Facultad de Derecho de la Universidad Diego Portales, Santiago de Chile, 2006.

\section{Documentos electrónicos}

NÁQUIRA, Jaime et al. "Principios y penas en el derecho penal chileno". En: Revista electrónica de ciencia penal y criminología, 2008.

Disponible en: http://criminet.ugr.es/recpc/10/recpc10-r2.pdf. Fecha última consulta: 04 de Marzo de 2013.

Facultad de Derecho y Ciencias Sociales - Universidad de Valparaíso - Chile 


\section{Revistas}

FERRAJOLI, Luigi. "Derecho penal mínimo y bienes jurídicos fundamentales". En: Revista de la Asociación de Ciencias Penales de Costa Rica. Año 4, N 5. Marzo-junio de 1992. (Traducción del profesor Walter Antillón M., de la Facultad de derecho de la Universidad de Costa Rica).

\section{Informes}

Informe anual sobre Derechos Humanos en Chile, año 2005, hechos 2004, Centro de Derechos Humanos, Universidad Diego Portales.

Informe anual sobre Derechos Humanos en Chile, año 2006, hechos 2005, Centro de Derechos Humanos, Universidad Diego

Portales.

Informe anual sobre Derechos Humanos en Chile, año 2008, hechos 2007, Centro de Derechos Humanos, Universidad Diego

Portales.

Informe anual sobre Derechos Humanos en Chile, año 2011, hechos 2010, Centro de Derechos Humanos, Universidad Diego

Portales.

\section{Sentencias}

Sentencia Corte Interamericana de Derechos Humanos (2004): Caso Herrera Ulloa vs. Costa Rica.

Sentencia Corte Interamericana de Derechos Humanos (2009): Caso Perozo y otros vs. Venezuela.

Corte Interamericana de Derechos Humanos, Opinión consultiva OC5/85 de 13 de noviembre de 1985. La colegiatura obligatoria de periodistas, solicitada por el gobierno de Costa Rica.

\section{Congreso Nacional}

Actas Comisión de Seguridad Ciudadana y Drogas. Sesión No 56, 09 de Noviembre de 2011.

Revista de Ciencias Sociales - Número 62 (2013) - Universidad de Valparáíso - ISSN 0716-7725-Valparaíso, Chile 
Historia de la ley 19.567, Diario Oficial 01 Julio de 1998.

Historia de la ley 20.253, Diario Oficial 14 Marzo de 2008.

\section{Proyectos de ley}

Boletín $\mathrm{N}^{\circ} 7018-25$, que sanciona con mayor rigor las alarmas públicas. Boletín $\mathrm{N}^{\circ} 7155-25$ que sanciona a quienes participen en desórdenes públicos con el rostro cubierto.

Boletín $\mathrm{N}^{\circ} 7290-25$ que agrava las penas por los delitos de daños en cámaras de televigilancia, vehículos motorizados u otros bienes

destinados a implementar planes de seguridad pública.

Boletín $\mathrm{N}^{\circ} 7895-25$ que modifica el procedimiento sobre control de identidad que corresponde realizar a los funcionarios policiales.

Boletín $N^{\circ} 7975-25$ que fortalece el resguardo del orden público.

Boletín $\mathrm{N}^{\circ} 8223-25$ que penaliza la interrupción del tránsito con fines coativos.

Boletín $\mathrm{N}^{\circ} 8420-25$ que modifica el código penal con el objeto de retipificar el delito de desórdenes públicos.

Facultad de Derecho y Ciencias Sociales - Universidad de Valparaíso - Chile 